\title{
O debate teórico-metodológico no campo do secretariado: pluralismos e singularidades
}

\section{The debate theorical-methodological in field of secretariat: diversities and singularities}

\author{
Rosimeri Ferraz Sabino ${ }^{1}$ \\ Paulo Sérgio Marchelli
}

\begin{abstract}
Resumo
Neste artigo analisa-se a proposta de uma ciência do Secretariado, abordam-se referenciais teóricos sobre epistemologia e práxis, bem como se explora o universo da área nos aspectos de formação, gênero, condutas legais e cultura organizacional. Busca-se identificar os elementos correspondentes à cientificidade da área do secretariado e o grau de autonomia que se revela na ciência própria que lhe é atribuída. As conclusões confirmam o Secretariado como constituindo um campo interdisciplinar de conhecimentos, que se utiliza de várias ciências tanto com respeito à formação quanto à atuação profissional.
\end{abstract}

Palavras-chave: Secretariado, ciência, epistemologia, práxis

\begin{abstract}
The paper analyzes the proposal of a Secretariat's science. It discusses theoretical references about epistemology and praxis and explores the universe of the analyzed area on issues such as training, gender, legal conduct and organizational culture. It aims to identify the elements corresponding to the scientificity of the secretarial area and the autonomy degree which is in science itself assigned to it. The conclusions confirm the Secretariat as an interdisciplinary field of knowledge, which is used in various sciences concerning both training and professional performance.
\end{abstract}

Keywords: Executive secretariat, science, epistemology, praxis administrative

\section{Introdução}

Estudos recentes têm promovido interessantes debates a respeito da natureza do conhecimento no campo do Secretariado e suscitado a possibilidade da constituição de uma ciência unificada para a área. No entanto, esses estudos sustentam-se em pontos de vista epistemológicos que excluem quase todos os elementos diretamente ligados à tradição teórica fundadora do campo, como a teoria das organizações. A construção da possível ciência secretarial não parece basear-se na independência irrestrita dos princípios teóricos que fundamentaram a área. O secretário executivo é essencialmente um assessor pessoal, que tem entre suas atribuições a tarefa de organizar as rotinas de líderes atuantes nas empresas ou em outras formas de organização, valendo-se fundamentalmente da ciência administrativa, que constitui o entorno conceitual básico para o desenvolvimento das tarefas que lhe são pertinentes.

A complexidade dos conhecimentos necessários ao secretário executivo caracteriza o desempenho profissional no qual a aplicação de várias teorias simultâneas, reunidas em um único sistema, aproxima-se muito mais de uma composição interdisciplinar do que de uma única ciência independente. Para esse sistema, parece ser

1 Mestre em Administração, Educação e Comunicação pela Universidade São Marcos/SP. Docente na Universidade Federal de Sergipe - UFS. Endereço: Campus São Cristóvão - Núcleo de Secretariado Executivo - Av. Marechal Rondon, s/n - São Cristóvão/Sergipe - Brasil - CEP: 49100-000 . E-mail: rf.sabino@ufs.br

2 Doutor em Educação pela Universidade de São Paulo - USP. Docente na Universidade Federal de Sergipe - UFS. Endereço: Núcleo de Educação, Av. Vereador Olímpio Grande - Campus Itabaiana - Itabaiana/Sergipe - Brasil - CEP: 49500-000. E-mail: marchelli@ufs.br

Artigo submetido em agosto e aceito em outubro de 2008 
necessária a interação de conhecimentos múltiplos que não atingem o estágio da unificação teórica independente, típica de uma ciência autônoma. Os argumentos que evocam a unificação do campo do conhecimento em Secretariado amparam-se em análises de aspectos particulares da função, contrariando o princípio da multiplicidade teórica que lhe tem sido característica. A complexidade da profissão é esboçada desde sua própria denominação, que é envolta por dicotomias semânticas, polêmicas sobre a natureza do campo de atuação, divisão de gênero e fundamentação em teorias organizacionais, culturais e sociológicas. Dessa forma, a identificação dos objetos do conhecimento em Secretariado como complexos e múltiplos permite que se alargue seu domínio de investigação e que sejam reveladas as incontornáveis dificuldades da pretendida teoria unificadora. Os múltiplos pressupostos epistemológicos das teorias estudadas no campo secretarial não o coloca à margem da cientificidade, tampouco o resume à mera prática. Um debate teórico realmente enriquecedor para o campo deve, assim, valer-se da aplicação de pressupostos interdisciplinares.

Nesse sentido, o objetivo no presente trabalho é abordar o campo do secretariado em termos de algumas de suas múltiplas epistemologias, incluindo formação, gênero, condutas legais e cultura organizacional, de forma a identificar elementos correspondentes à limitação e à não cientificidade que se revelam na teoria unificadora que pretendem lhe atribuir. As conclusões confirmam o Secretariado como uma área de conhecimento interdisciplinar e com forte aplicação das teorias organizacionais.

\section{Teoria e prática profissional no campo do Secretariado Executivo}

A Filosofia entende a prática como sendo o trabalho que cada homem executa na natureza em contato com seus semelhantes, constituindo a sociedade. Essa prática, quando permeada pela reflexão crítica baseada no conhecimento conceitual, constitui a práxis. Identificam-se, assim, dois elementos contrapostos no processo de construção da práxis: por um lado as ações, por outro a reflexão crítica por meio da qual se constroem teorias.

Uma teoria deve ter o compromisso de utilidade científica e verificabilidade, sob pena de ser refutada desde o princípio. Construída justamente sob a égide da observação da realidade, uma teoria deve se constituir em um sistema de conceitos que orienta a prática humana em direção à práxis. Assim, a antítese representada pela confrontação entre o sistema teórico e a observação empírica, esboçada no âmbito da reflexão crítica constitui a práxis, que é a base da existência da cultura e da sociedade. No entanto, as correlações dialéticas implícitas na teoria da práxis nem sempre são encontradas no exercício diário da prática secretarial. Quando despojado de teorias que sejam capazes de assumir compromissos com a verificação empírica, o secretário conduz seu trabalho a esmo, de forma meramente instrumental, guiado por um conhecimento heterônomo forjado de tal forma que não se espera dele mais do que obedecer a regras para operar determinada máquina ou processar sistemas conceituais já prontos.

No âmbito meramente prático, de pouco ou mesmo nada em termos de teorias e reflexões científicas os secretários precisam dispor para realizar seu trabalho. Nesse caso, a eles se imputa meramente saber operar instrumentos ou pensar segundo conceitos acabados, sem nunca explorar a possibilidade de aperfeiçoar seu conhecimento a respeito do contexto organizacional, para atuar com base em princípios teóricos passíveis de cientificidade. O cotidiano de trabalho no campo do Secretariado tem exigido competências técnicas que são meramente regras de como conduzir ações tais como a produção e o arquivamento de documentos, não se pretende, assim, nada além da aplicação de simples rotinas.

Os que defendem ser a prática secretarial não mais do que a aplicação de regras que visam zelar pelo funcionamento das rotinas burocráticas nas organizações, afirmam que para isto não há necessidade de nenhuma ciência: basta ao secretário observar as rotinas, se os membros da organização estão cumprindo os estamentos, assessorá-los, registrar suas decisões e encaminhá-las para às instâncias de execução. O secretário assemelha-se mais ao zelador do edifício do que realmente ao síndico que toma as decisões anuídas pelo conselho, submete-se, assim, dentro da estrutura organizacional das empresas à condição de mero assessor burocrático. Ao secretário, caracterizado como dotado de conhecimentos anteriores à práxis científica, pede-se sempre que seja um profissional capaz de redigir, de organizar documentos, de observar os procedimentos da rotina administrativa, mas a ele não é dado o poder de decidir sobre os desígnios da organização com a qual colabora. Seu trabalho em geral é visto como complementar e secundário, pois se entende que ele não age 
segundo as categorias do juízo empírico emprestadas a outros profissionais como os administradores, advogados e contabilistas. O secretário é, quando muito, um consultor dentro das organizações. No caso das empresas, seu trabalho é colocado como apêndice daquele executado pelos profissionais que ocupam posições diretoriais e gerenciais. Nos setores da governança, também é incomum os secretários ocuparem posições centrais dentro dos quadros estruturais.

A natureza secundária atribuída ao trabalho do secretário explica-se pelo fato de que as tarefas correspondentes têm sido historicamente executadas pelas mulheres. Desse mode, recebe o mesmo tratamento de discriminação a elas atribuído pelas sociedades tradicionais. Truss (1993) esclarece que o Secretariado na Inglaterra, França e Alemanha é uma ocupação de gueto feminino, ou seja, um trabalho culturalmente atribuído às mulheres. A autora corrobora sua tese por meio da análise de questionários e entrevistas aplicados a empresas dos três países. Assim, no Secretariado, os quatro pilares do conhecimento - conhecer, fazer, conviver e ser - ainda hoje são colocados em termos da condição de inferioridade e dominação imposta às mulheres no contexto da divisão social do trabalho, reduzindo-se drasticamente sua abrangência teórica e seu alcance científico. Dessa forma, por questões de gênero, assume-se uma posição reducionista na leitura da realidade objetiva da práxis do secretariado.

Certamente, as competências do saber fazer podem ser consideradas pelos empregadores, mas não servem por si sós, pois estão profundamente associadas à maneira como se estabelece a divisão do trabalho na sociedade. Considerada como pré-científica e retirada do círculo de racionalidade com que Ford e Taylor inauguraram a moderna ciência da administração, a práxis do secretariado é identificada apenas com a capacidade de saber fazer. Porém, a competência ditada pelo saber fazer é apenas mais um dos aspectos considerados pela ciência administrativa, que ao estabelecer os princípios para o desenvolvimento de teorias organizacionais, volta-se explicitamente para o entendimento da natureza que o trabalho humano assume nas organizações. Dessa forma, para a elaboração de correspondências como tarefa cotidiana, não basta ao secretário saber redigir e digitar, mas também conhecer o processo de comunicação estabelecido na organização e suas implicações. Assim, o Secretariado não deve ser considerado apenas como prática profissional, mas também como práxis que incorpora conceitos teóricos, consciência reflexiva e domínio de teorias científicas. É preciso que o secretário tenha conhecimentos específicos que levem à compreensão da complexidade teórica do seu trabalho prático.

A prática do secretário executivo configura-se como atividade de assessoria com vistas à realização de objetivos organizacionais. Mas a práxis do secretariado vai além disso, e envolve categorias de análise que visam a compreender o entorno conceitual em que as atividades se desenvolvem. Em estudo sobre as práticas profissionais do secretário no mercado norte-americano, Reich (1994, p. 168) encontrou três grandes grupos distintos de trabalhadores: executores de serviços rotineiros mecanizados, como recuperação em banco de dados; produtores de serviços pessoais, como administração de agenda e compromissos; e criadores de serviços analítico-simbólicos, sob a forma de apoio a tarefas executivas complementares. O autor considera que esses grupos constituem um sistema de categorias baseado em níveis de dificuldades progressivas no que toca às habilidades necessárias para o desempenho das funções correspondentes. Do primeiro grupo não se exigem mais do que conhecimentos operacionais de digitação em sistemas de informações fechados, tais como o preenchimento das planilhas de um banco de dados, em que pouco conhecimento analítico é necessário. Já no segundo grupo, a própria natureza de serviço pessoal adjunto às tarefas do executivo está sujeita às condições decorrentes da práxis no campo psicológico, conforme enunciado por Macdonald (1988, p. 15): "quando se seleciona uma secretária executiva não se pode considerar apenas as habilidades requeridas, mas também a personalidade do executivo com quem ela trabalhará". Para Allport (1945) um secretário será ideal na medida em que atender não somente aos aspectos técnicos, mas também psicológicos, entendidos aqui como relativos ao temperamento necessário para a relação de trabalho com o seu executivo. O terceiro grupo é constituído pelos profissionais secretários que operam sistemas de conceitos dentro de uma condição coerente com a práxis científica, subentendendo-se que a análise simbólica seja uma característica típica dessa práxis.

É importante observar que tanto Macdonald quanto Allport revelam em suas considerações a questão negativa de gênero implicada na profissão se secretário. O segundo autor, inclusive, faz alusão à relação de trabalho da secretária com o "seu executivo", suscitando de alguma forma que ela é uma espécie de propriedade daquele. Observa-se a presença do aspecto negativo de gênero ligado à prática desta profissão no relatório da Equal 
Opportunity Commision, no qual estão descritas as tarefas típicas da secretária administrativa: “[...] preparar material de apresentação de relatórios; compilar (arquivos, relatórios e outras fontes), fatos pertinentes para assistir diretores em análises e tomadas de decisão; manter calendário com as datas limites das atividades; e assegurar que o trabalho esteja sendo feito em tempo hábil" (RidgewayI, 1982, p. 17). Assim, o trabalho do secretário executivo desenvolve-se como linha de staff pessoal e especializado, em que se utilizam teorias de planejamento, organização e controle; e, em relação aos aspectos de gênero, apresenta-se como uma atividade caracterizada pela prestação de serviços da mulher para o homem.

Mesmo que o Secretariado Executivo, como área do conhecimento, estivesse historicamente a reboque da ciência e se formasse no âmbito de uma conjugação social extremamente forjada por relações de gênero, muito ele se distanciou do trabalho baseado na repetição e memorização de regras práticas, passíveis de simples treinamento para serem executadas. Na própria relação de gênero implícita nas estruturas organizacionais aparece o enfrentamento de eventos não previstos, o que demanda dos executivos comportamentos e atitudes peculiares a cada situação. Estando a secretária na posição de staff pessoal, obviamente deverá se alinhar ao posicionamento de seu executivo. De acordo com as situações vividas pelo executivo, a secretária terá que desenvolver novas rotinas, novas relações, novos processos administrativos, enfim, novos padrões para a eficiência e eficácia do seu trabalho.

A natureza da práxis secretarial é considerada, então, multidisciplinar, na qual se utilizam teorias diversas de forma interdisciplinar, com vistas a atingir a coerência científica necessária à compreensão da realidade da função, bem como de seus aspectos práticos. Isto fica claro desde a formação do indivíduo para a função, em que "[...] são trabalhados conteúdos de diferentes áreas do conhecimento: Administração, Contabilidade, Filosofia, Sociologia, Direito e outras que contribuem com a atuação profissional" (Hoeller, 2006, p. 5). Muito se tem aventado sobre a possível identificação de uma unidade de saberes, construída a partir de conceitos, argumentos e métodos de distintas ciências, capazes de atender à complexidade da práxis proposta. $\mathrm{O}$ fazer do secretário tem se baseado, entretanto, na aplicação de conhecimentos múltiplos, gerados como forma de interação entre disciplinas que possibilitam o entendimento da práxis de cada uma separadamente.

O movimento em direção ao conhecimento unificado situa-se no estágio correspondente à transdisciplinaridade, cujo conceito impõe um nível de colaboração entre disciplinas que elimina a possibilidade de redução conceitual a qualquer uma das envolvidas: "[...] É a etapa superior de integração. Trata-se da construção de um sistema total, sem fronteiras sólidas entre as disciplinas, ou seja, de uma teoria geral de sistemas ou de estruturas, que inclua estruturas operacionais, estruturas de regulamentação e sistemas probabilísticos, e que una estas diversas possibilidades por meio de transformações reguladas e definidas." (Santomé, 1998, p.70).

Sob a égide da transdisciplinaridade, o fazer baseado em tarefas de staff administrativo e pessoal necessário ao segundo grupo da hierarquia profissional de Reich (1994), por exemplo, estaria sujeito a conhecimentos do campo da Psicologia que abrange áreas de aplicação dos princípios básicos da Administração, como planejamento, organização e controle. É algo próprio da evolução apresentada no Quadro 1, que especifica as mudanças de uma situação anterior já ultrapassada para o que poderia esboçar uma ciência secretarial. 
Quadro 1: As mudanças na atividade secretarial.

\begin{tabular}{ll}
\hline \multicolumn{1}{c}{ AS MUDANÇAS NA ATIVIDADE SECRETARIAL } \\
\hline O que se fazia antes & O que se está fazendo hoje \\
\hline Datilografia & $\begin{array}{l}\text { Gerenciamento de sistemas de informação por meio do } \\
\text { controle de rotinas automatizadas multimídia (editores de } \\
\text { texto, agendas e planilhas eletrônicas, bancos de dados, } \\
\text { etc.) }\end{array}$ \\
\hline Envio e recebimento de correspondências & $\begin{array}{l}\text { Coordenação de fluxo de informações e de papéis no } \\
\text { departamento, muitas vezes encaminhando-os para uma } \\
\text { equipe de apoio. }\end{array}$ \\
\hline Provisão de material & $\begin{array}{l}\text { Coordenação de compras, cotação de materiais com } \\
\text { fornecedores alternativos e administração dos custos do } \\
\text { departamento. }\end{array}$ \\
\hline Coordenação de viagens & $\begin{array}{l}\text { (incluído no segundo item) } \\
\text { Atendimento de telefones e visitas }\end{array}$ \\
\hline $\begin{array}{l}\text { Atendimento com enfoque de qualidade total a clientes } \\
\text { internos e externos. }\end{array}$ \\
Manutenção de arquivos & $\begin{array}{l}\text { Organização de sistemas de dados e informações em } \\
\text { arquivos físicos e eletrônicos. }\end{array}$ \\
\hline Agendamento de reuniões & $\begin{array}{l}\text { Apoio a reuniões, já que os próprios executivos marcam } \\
\text { seus compromissos utilizando sistemas informatizados } \\
\text { de comunicação interna. }\end{array}$ \\
\hline
\end{tabular}

Fonte: Guimarães (2001, p. 38).

A despeito da possibilidade ou não de se criar uma teoria transdisciplinar no âmbito do secretariado, todas as práticas correspondentes contém uma estrutura comum que atende à organização de processos administrativos para auxiliar o executivo em suas atribuições, servindo-o em termos do planejamento e controle de tarefas específicas. Obviamente, conhecimentos transversais são necessários ao secretário para o desenvolvimento dessas práticas, mas tornam-se especificidades que partem sempre do ato de administrar. Tomando-se, por exemplo, a tarefa de arquivar atribuída aos secretários, pode-se dizer que ela representa a criação, implementação e manutenção de sistemas de arquivos ativos e inativos de documentos ou dados. Para isso, o secretário necessita de conhecimentos sobre Arquivística e sobre Direito, este último relacionado à guarda de documentos legais. Mas essas disciplinas não podem ser aplicadas no vazio. Elas estão embasadas em princípios organizacionais com características especificamente administrativas, que diferem nas demais circunstâncias em que a Arquivística ou o Direito se aplicam. Assim, iniciando-se no plano da Administração, o movimento da práxis no domínio do secretariado remete para saberes que oscilam entre o pensamento multidisciplinar, resultante de conhecimentos em áreas diversas, e saberes interdisciplinares, decorrentes da justaposição de várias disciplinas, não constituindo, no entanto, uma construção teórica autônoma.

\section{Epistemologia, teoria do conhecimento ou o espírito científico no campo do Secretariado}

Alguns autores, como Hoeller (2006) e Nonato Júnior (2008) admitem a possibilidade de uma teoria do conhecimento ou uma epistemologia para o secretariado. Assim, pensam em estabelecer um sistema teórico unificado que inclui desde os aspectos técnico-operacionais da área até preceitos científicos capazes de permitir a formulação e validação de hipóteses por meio de experimentos empiricamente concebidos. Tais autores argumentam que os estudos descritivos e exploratórios de pesquisa realizados na área demonstram a necessidade de uma ampla articulação entre teoria e prática para que o campo do conhecimento em Secretariado se legitime como válido, em termos do consenso epistemológico vigente sobre o que seja a ciência. O esforço desses autores para fundamentar o Secretariado como ciência inclui Popper (1975) e Bachelard (2002), primeiro porque é palatável ao gosto popperiano definir a epistemologia como "o estudo crítico dos princípios, das hipóteses e dos resultados das diversas ciências, destinado a determinar sua origem 
lógica, seu valor e seu alcance objetivo" (Lalande, 1985, apud Nonato Júnior, 2008,p. 3); segundo porque são de inspiração bachelardiana as seguintes linhas referentes a uma pesquisa realizada sobre o assunto:

Ao longo do levantamento de dados, identificaram-se diversas situações e depoimentos que apontavam para a existência de obstáculos epistemológicos à teoria do conhecimento em Secretariado. Em análise final do diário de pesquisa, percebeu-se que $75 \%$ dos registros apontavam questões de desafio ao estabelecimento de uma teoria secretarial. Também a análise dos projetos e o material do ciclo de debates confirmavam esta assertiva. Por fim, encontrou-se na teorização bibliográfica realizada a categoria Obstáculos Epistemológicos que possibilita a discussão dos dados agrupados de maneira transversal, buscando-se entender os desafios ao estabelecimento de uma teoria secretarial. (Nonato Júnior, 2008, p. 5 , grifo do autor)

$\mathrm{O}$ autor se pergunta sobre quais seriam os principais desafios ao estabelecimento da epistemologia do Secretariado, e justifica que sua preocupação se dá pela necessidade, atual, do debate de temas contemporâneos ligados à ordem científica e cultural da profissão. Argumenta que os debates têm sido tradicionalmente silenciados por uma prática de trabalho que esconde o necessário diálogo sobre as condições e a possibilidade do florescimento de novos e autênticos caminhos metodológicos. A noção de obstáculo epistemológico, sabese, é devida a Bachelard (2002). Na ótica de Nonato Júnior, para instaurar o conhecimento científico na área secretarial é preciso resolver problemas a longo prazo, os quais constituem os obstáculos epistemológicos em questão e compreendem más interpretações do senso comum, estereótipos, limitações teóricas e conclusões previamente equivocadas. Como não são abordados, os obstáculos epistemológicos produzem estagnação intelectual, inércia e até mesmo regressão do conhecimento, de forma a obstruir o desenvolvimento científico do Secretariado. Um problema fundamental é a inserção da área no campo das Ciências Sociais Aplicadas, para as quais haveria o falso consenso que não necessitam de fundamentação teórica. Daí a dificuldade de se ver o Secretariado como uma área do conhecimento científico.

A posição de Hoeller não é exatamente a mesma de Nonato Júnior:

[...] O curso de Secretariado Executivo não é uma ciência no sentido conhecido e explicado neste trabalho, mas sim um campo de estudo de aplicação. [Porém], nem só de prática subsiste um curso e o conhecimento humano, há de se compor e complementar o valor dos conhecimentos, como componentes intelectuais necessários à construção do mundo. Portanto, o curso de Secretariado Executivo é voltado para diagnosticar e solucionar os problemas da realidade empresarial, sempre baseada em referências teóricas [...]. (Hoeller, 2006, p. 145).

Porém, Nonato Júnior (2008, p. 6) declara que "é necessário e urgente estabelecer significativa discordância dessa afirmativa [de Hoeller]", pois se deve compreender que ciência e prática não se excluem mutuamente. Declara ainda, na mesma página, que "a prática apenas efetua-se como tal quando está plena de fundamentação, senão torna-se apenas uma ação interventiva". No entanto, na posição de Hoeller, não há claramente desconhecimento sobre a dimensão teórica do campo do Secretariado Executivo, pelo contrário, a autora a reafirma reiteradamente, pelo menos no que tange à natureza do curso ao qual se refere: "[...] o curso não somente procura uma nova tomada de posição teórica, mas também pretende transformar em ação concreta os resultados de seu trabalho. Procura conhecer para aplicar, para realizar uma tomada de decisão executória". (Hoeller, 2006, p. 143).

$\mathrm{Na}$ verdade, os dois autores concordam que o secretariado não pode mais prescindir de bases teóricas capazes de elevá-lo à categoria de ciência, apenas um deles é mais incisivo sobre o assunto, enquanto o outro deixa entrever que o problema está de certa forma resolvido dentro dos cursos de formação profissional existentes. É no campo do ensino que boa parte dos trabalhos em secretariado tem-se consumado, com alcance limitado em termos de discussão epistemológica. Nonato Junior generaliza o problema e faz dele mais um obstáculo, ao apontar para a escassa teorização de uma bibliografia que coloca o Secretariado como tributário da Sociologia, da Administração, da Linguística, da Arquivística, do Direito, etc, mas nunca como uma ciência em si mesma. Ele conclama que: 
[...] Não há mais de se ancorar os estudos e práticas do Secretariado em epistemologias de outras áreas [...]. $O$ conhecimento secretarial já atinge tamanha complexidade de experiências e pesquisas que necessita da discussão de uma Teoria do conhecimento própria, afirmando seus objetos e objetivos de estudo, fortalecendo o Secretariado em sua unidade de informação. [...].(Nonato Júnior, 2008, p. 9) .

De fato, o campo secretarial tem-se baseado tradicionalmente em pressupostos teóricos multidisciplinares para estabelecer o corpo central de suas doutrinas. Métodos de pesquisa, por exemplo, em que se utiliza substancialmente o levantamento de dados em empresas, como a investigação sobre a trajetória e as perspectivas para a profissão no Estado de Mato Grosso que Squinelo e Bertoldo (2002) realizaram. Tem-se, ainda, os trabalhos de Schvinger, Prado e Castro (1985) e de Moretto e Jesus (1999), o primeiro voltado para o estudo sobre o papel feminino na profissão, e o segundo, para as tendências da área no Brasil.

Assim, trabalho após trabalho os pesquisadores do campo secretarial têm utilizado subsídios epistemológicos de várias ciências para a abordagem teórica. O principal foco empírico está situado nas empresas, espaço tradicional de ocupação dos secretários, juntamente com as áreas da governança. Um bom exemplo é o trabalho já citado de Truss (1993), que analisou a predominância de gênero na profissão na Inglaterra, França e Alemanha. Concluiu-se, nesse trabalho, que o secretariado é um gueto feminino, com base em uma pesquisa de natureza qualitativa em que se adotou, para capturar a complexidade das diferentes experiências das mulheres na situação de trabalho, um procedimento metodológico que não pode ser reduzido a um único campo de. A abordagem desenvolvida pela autora foi exploratória e investigou a cultura do trabalho secretarial no campo das organizações empresariais, como fenômeno sociológico, dentro dos países observados, baseando-se no princípio de considerar tanto o espaço organizacional, quanto as macro-configurações que circunscrevem a ocorrência desse trabalho. A abordagem envolveu a divisão do trabalho nas organizações como manifestação da cultura nacional, concentrando-se nos aspectos tangíveis dessa cultura, como o sistema de educação e de formação. Assim, a autora procurou desvendar a complexidade dos dados levantados nas instituições organizacionais por meio das atenuantes culturais localizados no nível social.

Ridgeway (1982) baseia-se em aspectos específicos das funções de trabalho nas organizações para reportar as características das mudanças que ocorrem quando os profissionais secretários do Reino Unido migram de uma empresa menor para outra de maior dimensão. Quando assim o fazem, os secretários têm suas funções ampliadas, o que na realidade não inclui novas responsabilidades, nem aumento do poder quanto a tomar decisões e efetuar mudanças no esquema de criatividade, normalmente consideradas necessárias a um trabalho de estatuto mais alto. Tipicamente, explica o autor, os alargamentos da função secretarial, que ocorrem da pequena para a grande empresa, não implicam o aumento da responsabilidade na tomada de decisões, pois se verifica que os gestores e dirigentes empresariais se eximem em qualquer circunstância de delegar funções administrativas de alto nível aos seus secretários. Esse resultado explica porque nas empresas os secretários executivos têm desempenhado funções caracteristicamente subalternas, em termos da escala de tomada de decisões, o que representa um dado característico das culturas organizacionais nos diversos países do mundo.

Macdonald (1988), no entanto, aponta que determinadas mudanças relacionadas ao aumento da importância do secretário executivo nas estruturas empresariais podem ser observadas na Inglaterra, caracterizando melhorias decorrentes de uma progressiva valorização da profissão. Houve momentos, explica a autora, que em todo o mundo capitalista, as mulheres, diante da incerteza frente a um mercado de trabalho restrito, tornavam-se secretárias, faltando-lhes outras opções de carreira. Embora sempre houvesse profissionais altamente qualificados desempenhando funções secretariais nas organizações, não é distante o tempo em que a maioria tinha treinamento inadequado, pouca qualificação e falta de uma real motivação para se firmar no trabalho. Havia também o agravante de que muitas entidades patronais, que infelizmente prosperam até hoje, recrutavam o trabalho secretarial sem exigir nenhuma formação na área, oferecendo posições limitadas de carreira profissional, nada mais do que serviços de digitação ou até mesmo ocupações de limpeza. Porém, diante das novas concepções das teorias organizacionais que consideram cada membro da corporação como um colaborador essencial para a definição de estratégias e realização de objetivos, os secretários mais bem formados disponíveis no mercado de trabalho passam a ocupar cada vez mais posições de destaque dentro dos quadros empresariais. 
Como se vê em geral na literatura, as abordagens sobre a práxis secretarial são incorporadas pelas mais amplas epistemologias, a exemplo de tantas outras além das que foram acima narradas. Como laboriosidade de gênero feminino, até agora se deu que a teoria gerada pela práxis secretarial tem pouco valor científico, não representando mais do que a reunião difusa de conceitos extraídos das Teorias Organizacionais, do Direito, da Lingüística, da Arquivística, entre outros campos não menos exuberantes de conhecimentos. Os que se propõem a defender o Secretariado como ciência independente estão certamente como Dom Quixote, brigando com moinhos de vento, pois sua imaginação os leva a identificar uma epistemologia que nada mais é do que um conjunto de pás giratórias em movimento contínuo, devido às engrenagens de múltiplos campos de abordagem. Da mesma forma, no famoso livro de Cervantes, Dom Quixote atacou o moinho de vento, porque uma rajada mais forte acelerou o movimento das pás e fez o cavalo Rocinante empinar-se assustado, os construtores da ciência secretarial unificada e independente dos demais campos do conhecimento não sabem muito bem que estão a produzir apenas quimeras literárias. Mas Cervantes se propunha exatamente à literatura, diferentemente dos cientistas do Secretariado que devem evitar as teorias irreais, uma vez que milhares de profissionais se formarão no futuro sob sua égide.

\section{As perspectivas da ciência do Secretariado como conhecimento interdisciplinar}

Na visão popperiana sobre a natureza da ciência as teorias são consideradas possíveis de contestação quanto à suposição de sua falsidade: "É verificando a falsidade de nossas suposições que de fato entramos em contato com a "realidade" (Popper, 1975, p. 331). A verificação da falsidade constitui o caminho para progresso da própria ciência, a qual tem sua tarefa "em parte teórica - explicação - e em parte prática - predição e aplicação técnica." (Popper, 1975, p. 321). Além disso, "recuso-me a aceitar a concepção de que, em ciência, existam enunciados que devamos resignadamente aceitar como verdadeiros, simplesmente pela circunstância de não parecer possível, devido a razões lógicas, submetê-los a teste.” (Popper (1975, p. 50).

Assim, a investigação científica deve considerar apenas hipóteses possíveis de serem testadas, a submissão de um enunciado teórico à experiência torna-se um dos critérios que permitem a sua validação como conhecimento aceito. Uma vez aceito, o conhecimento é dito verdadeiro.

No entanto, "princípios constituídos por enunciados verdadeiros podem perfeitamente gerar teorias falsas" (Marchelli, 2004, p. 121), como o mundo plano produzido pelo axioma das paralelas de Euclides, inicialmente aceito como verdadeiro, mas que se mostrou, posteriormente na história da ciência, como uma falsa ideia a respeito da 'realidade'. Tem-se ainda que: "para uma idéia ser considerada científica é necessário que seja comprovável. É necessário, porém não basta. Com efeito, uma idéia pode ser comprovável apesar de ser incompatível com conhecimento científico, e neste caso não a aceitaremos como científica." (Bunge, 1980, p. 24).

Em Bunge (1969) verifica-se a classificação das ciências em dois grandes grupos: formais, com a lógica e a matemática, e factuais, com as ciências naturais e as sociais. As ciências formais tratam de abstrações e interpretações sobre entes conceituais, não lhes interessando a investigação sobre fenômenos empíricos. É no grupo das factuais que observação e experimentação ocorrem como formas de comprovação ou refutação de hipóteses. São os objetos estudados que definem uma ciência como formal ou factual. Nas ciências formais os objetos são conceituais, nas factuais eles são concretos. Bunge (1980) esclarece que não é possível caracterizar um objeto como concreto e conceitual ao mesmo tempo. Ao se relacionar esse fato à discussão da ideia de considerar o Secretariado como ciência autônoma, é necessário identificar pelo menos um dos seus objetos de estudo que seja independente de outra ciência. No âmbito dos cursos de formação tem-se:

[...] O curso está na área da ciência factual, utiliza-se do método indutivo, no campo social - área de humanas, proveniente de várias ciências puras como: direito, economia, política, sociologia, lingüística e outras (...) O objeto do conhecimento é, então, para o pensamento, um processo de sintese, um resultado [...]. (Hoeller, 2006, p. 144),

Tal como os cursos de formação, a ciência do Secretariado estaria no grupo factual, mesmo que seu objeto material não esteja claro na citação de Hoeller. A citação é importante na medida em que expõe o processo de 
síntese necessário para o estabelecimento do conhecimento secretarial. Tal síntese é constituída vcom base em múltiplas disciplinas, deixando entrever o aspecto interdisciplinar do conhecimento estabelecido.

A busca dos objetos de conhecimento em Secretariado impõe estabelecer suas origens históricas e as instâncias sociológicas que permitem a identificação das características particulares sobre o ofício. Em sentido amplo, um secretário é um assessor de líderes, aspecto pelo qual ele é associado historicamente ao trabalho do escriba da antiguidade, indivíduo que colocava o domínio da escrita a serviço da administração real e sacerdotal (Marrou,1990). Os escribas faziam parte de uma classe culta e bastante prestigiada à época, tanto pela atuação próxima a governantes que lhes davam livre trânsito em áreas cerceadas ao povo, como pelo conhecimento da leitura e escrita, habilidades raras até mesmo entre os faraós.

Na sociedade patriarcal sumeriana (cerca de 3.000 a.C) a função de escriba era exercida exclusivamente por homens. Essa característica manteve-se por muitos séculos entre os que exerceram a função de assessores dos grandes governantes dos Estados e da Igreja, conforme corrobora Maquiavel no Capítulo XXII de sua obra magna, quando escreve sobre os secretários que os Príncipes têm junto de si - "De his quos a secretis principes habent".: "A primeira conjectura que se faz da inteligência de um senhor resulta da observação dos homens que o cercam; quando são capazes e fiéis, sempre se pode reputá-lo sábio, porque soube reconhecê-los competentes e conservá-los " (1996, p.115).

Observa-se na História que a função do secretário como escrevente e assessor pessoal foi exercida por indivíduos nos quais os líderes políticos e religiosos depositavam extrema confiança, o que imprime à relação secretário-líder um aspecto de deferência. Esse tipo de relação, mantida até início do século XX, sofreu mudanças substanciais a partir da Primeira Guerra Mundial. Nessa época, as primeiras teorias administrativas desenvolveram as bases da estrutura empresarial moderna, considerando a produção dos trabalhadores, a direção da empresa e as relações interpessoais nas organizações. O trabalho secretarial passou a caracterizar a extensão da capacidade de ação do líder assessorado. Um dos estudos que muito colaboraram para essa noção é o de Alfred Marshall que menciona: "Temos agora que considerar mais cuidadosamente as diversas funções que os homens de negócio desempenham e a maneira pela qual essas funções são distribuídas entre os dirigentes de uma grande empresa" (Marshall, 1982, p.249). O autor utilizou também o exemplo do pequeno empresário, que trata pessoalmente de todos os aspectos do negócio, re a quem pouco tempo resta para refletir sobre muitas questões relevantes ao desenvolvimento de sua empresa. Nesse sentido, no universo das atividades de um gerente é possível admitir uma consequente atribuição de tarefas rotineiras aos secretários, liberando o tempo do líder para trabalhos considerados mais relevantes à empresa.

Simultaneamente ao surgimento das primeiras teorias administrativas, os postos secretariais tornaram-se predominantemente ocupados pelas mulheres, condição reforçada pela convocação dos homens para as frentes de batalha nas duas guerras mundiais da primeira metade do século XX. As características femininas de organização do lar foram consideradas positivas aos novos ambientes das fábricas, onde as mulheres passaram a compor grande parte do quadro de empregados. No entanto, ao mesmo tempo em que essas características contribuíram para o ingresso da mulher na ocupação, colaboraram para o estereótipo de uma função voltada para tarefas domésticas, prestadas como atendimento pessoal a um executivo. Referindo-se à visão dos executivos sobre suas secretárias, Garcia (1999, p. 111) escreve: "Para servir café para as visitas, não há charme maior que impressione os visitantes e faça crescer a auto-estima do indivíduo que a tem [a secretária] como subordinada".

Observa-se que a ocupação da função, em escritórios de organizações, não só deixou de ser masculina, como também recebeu a herança de discriminação sofrida pelas mulheres no mundo produtivo. Esse fato é interpretado como "ingenuidade das expectativas" sobre a sociedade capitalista:

[...] logo ficava evidente que, se o acesso de mulheres a ocupações antes "masculinas" oxigenava terrenos-chave onde se tecem as interações e se estabelecem as formas de sociabilidade, no trabalho e fora dele, tal acesso distava muito, tanto de exprimir igualdade de oportunidades e de eliminar as marcas da segregação (ocupacional, salarial, simbólica), promovendo a almejada eqüidade de gênero na esfera pública, como de alavancar de modo exaustivo todo um genérico grupo - as mulheres. Ao contrário, passam a existir novas formas de distinguir, material e simbolicamente, não somente os 
homens e as mulheres, mas também diferenciar as relações de trabalho em que se inserem, os destinos ocupacionais que almejam e alcançam, os padrões salariais que lhes são atribuídos e as expectativas sociais construídas entre os que classificamos como "homens" e as que classificamos como "mulheres". (Guimarães, 2004, p. 146).

No entanto, no conceito amplo de "assessor de líderes", a função do secretário também abrange a alçada governamental: os secretários de Estado. Se no âmbito empresarial a função sofreu a mudança de gênero por uma contingência social, na esfera do poder político a situação mostra-se contrária. $O$ acaso não permeia a presença de mulheres nos cargos de secretários de Estados, mas, sim, a reivindicação. Estudos do Program for the Support of Women's Leadership and Representation - PROLEAD relatam que o ingresso da mulher no âmbito político ocorreu a partir do renascimento da democracia, com a queda de ditaduras ao final dos anos 80 e 90. Tradicionais partidos políticos, ainda liderados por homens, se depararam com um mercado competitivo para suas eleições. Isso despertou o interesse pela conquista eleitores também entre o público feminino. As mulheres identificaram nesse ambiente uma oportunidade para lançarem seu pleito de quotas, previstas em leis, que obrigassem à reserva de percentagem mínima de candidaturas femininas. Surpreendentemente, a causa foi acolhida em vários países por políticos homens. Assim, identifica-se claramente que as mulheres passaram a ocupar por fatores antagônicos: o primeiro por ter gerado uma função no âmbito empresarial ligada às habilidades femininas, sem representação de poder e como solução a um problema corporativo; no segundo, por ter criado uma oportunidade de ingresso no âmbito político, em igualdade com o poder masculino e sob reivindicação.

Essa análise é relevante à identificação do próprio objeto de conhecimento do secretariado. A função mostra-se envolvida em ambientes diversos, os quais implicam as tarefas desempenhadas e na alçada de poder de atuação. No ambiente corporativo, a função trata de assessoria pessoal em tarefas administrativas, já no ambiente político está ligada à assessoria nas decisões de governantes. Enquanto um ocupa-se de tarefas que organizam o dia-a-dia do seu executivo, em nível operacional, o outro desenvolve ações que garantam a execução dos planos de governantes, em nível estratégico. Constata-se isso no caso brasileiro sobre as atribuições do Secretário Executivo da Secretaria-Geral da República, constantes na Lei 11.204/05, destacando-se aqui os itens IV e V, do Artigo $3^{\circ}$.:

Art. $3^{\underline{o}}$ - À Secretaria-Geral da Presidência da República compete assistir direta e imediatamente ao Presidente da República no desempenho de suas atribuições, especialmente: [...]

IV - na promoção de análises de políticas públicas e temas de interesse do Presidente da República e na realização de estudos de natureza político-institucional;

$V$ - na formulação, supervisão, coordenação, integração e articulação de políticas públicas para a juventude e na articulação, promoção e execução de programas de cooperação com organismos nacionais e internacionais, públicos e privados, voltados à implementação de políticas de juventude. (Lei 11.204/05).

Em ambos os casos, comprova-se que o secretário exerce assessoria, porém em níveis de atuação distintos, impondo, portanto, conhecimentos distintos. No caso brasileiro, onde o Secretariado é reconhecido como profissão, em nível técnico e executivo, perante a Lei 9.261/04, as tarefas a ele atribuída, em nível executivo, são:

I - planejamento, organização e direção de serviços de secretaria;

II - assistência e assessoramento direto a executivos;

III - coleta de informações para a consecução de objetivos e metas de empresas;

IV - redação de textos profissionais especializados, inclusive em idioma estrangeiro;

$V$ - interpretação e sintetização de textos e documentos; 
VI-(vetado);

VII - versão e tradução em idioma estrangeiro, para atender às necessidades de comunicação da empresa;

VIII - registro e distribuição de expediente e outras tarefas correlatas;

IX - orientação da avaliação e seleção da correspondência para fins de encaminhamento a chefia;

$X$ - conhecimentos protocolares. (Lei 9.261/04)

Observa-se que a lei brasileira que estabelece a função como profissão abrange apenas a dimensão dos serviços administrativos, o que se poderia denominar como um microcosmo do universo corporativo. Então como compreender o significado do termo "secretário executivo"? Pela busca em sua dicotomia de universalidades, como o fato de se tratar de um trabalho se assessoria, desenvolvida diretamente junto a líderes, em variados assuntos de interesse destes, que ganha a característica de pessoalidade. Isso difere a função de assessorias que atuam sobre um assunto em particular, como a jurídica, a de imprensa, etc. Dada a atuação orientada pelos interesses de quem oficialmente detém o poder - executivo de uma empresa ou líder governamental a função pode ser definida como staff para a execução de comandos de uma autoridade maior, servindo como canal entre líderes e liderados. Assim, é possível estabelecer o seguinte diagrama:

Figura 1: Diagrama da função secretarial nos âmbitos corporativo e político.

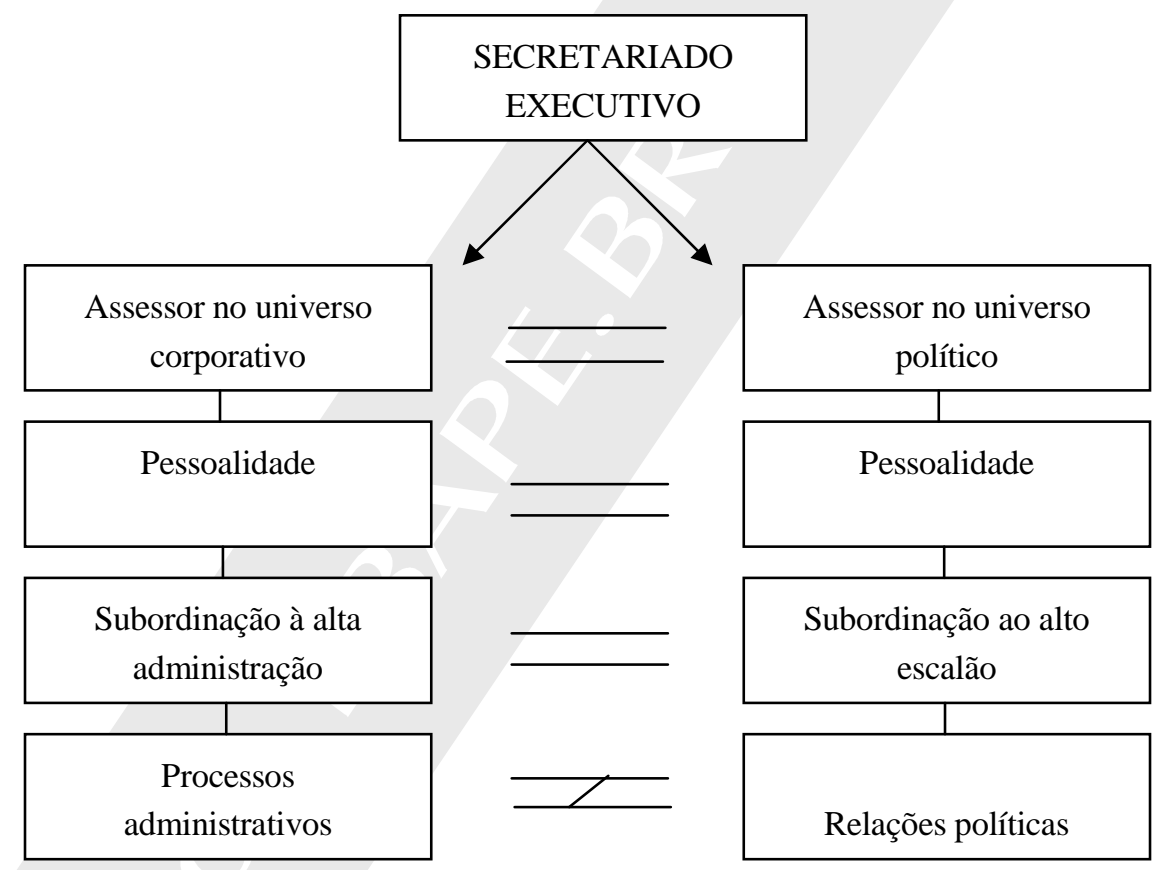

Dessa forma, embora haja correspondência semântica do termo nas duas dimensões, os conhecimentos requeridos para "o fazer" são distintos e, consequentemente, serão também distintos os seus objetos. No âmbito corporativo, o objeto do Secretariado são os processos administrativos e sua inter-relação com o sistema de gestão. Já no âmbito governamental, o objeto de estudo são as relações políticas e a articulação delas na sociedade. Ambos precedem conhecimentos teóricos interdisciplinares, mas em áreas distintas.

O Secretariado também se vê envolvido na discussão conceitual de profissão e ocupação. O título de profissão, originalmente atribuído pelas universidades medievais europeias, é outorgado por órgãos governamentais de acordo com o sistema legal de cada nação. Assim, a existência do título está submetida às condições peculiares dos países, o que implica cultura, interesses e entendimento sobre determinada ocupação. O secretariado desfruta da condição de profissão apenas no Brasil, embora conte com a formação específica em outros países. 
Também no caso da formação, há peculiaridades de acordo com os sistemas educacionais das regiões. Por exemplo, o secretário executivo brasileiro conta com a formação em nível de bacharelado, o que requer o mínimo de 2.400 horas, já no sistema educacional espanhol a formação ocorre em nível equivalente ao superior tecnólogo, com o mínimo de 1.300 horas.

O ensino para a ocupação, termo adotado neste trabalho pela abrangência também em realidade diversa da brasileira, comprova a necessidade de especialização, sob fundamentação teórica. Porém, a natureza da formação por si só não pode sustentar uma proposta científica unificada para o Secretariado no terreno epistemológico, como pretendem certos autores já relacionados:

"Se a natureza do conhecimento contemporâneo em Secretariado não fosse compatível com a teoria do conhecimento científico, não haveria a necessidade de oferta de cursos plenos de Bacharelado, uma vez que esta modalidade de curso trata de formar cientistas e intelectuais capazes de fomentar teorias do conhecimento nas profissões em que atuam". (Nonato Júnior,2008, p.7).

No sistema de ensino brasileiro o título de bacharel, conforme o Ministério da Educação (2008) está ligado à profissão: "São cursos que habilitam o portador a exercerem uma profissão de nível superior", e as diretrizes específicas para o Secretariado deixam clara essa relação pela seguinte menção:

"O bacharel em Secretariado Executivo deve apresentar sólida formação geral e humanística, com capacidade de análise, interpretação e articulação de conceitos e realidades inerentes à administração pública e privada, ser apto para o domínio em outros ramos do saber, desenvolvendo postura reflexiva e crítica que fomente a capacidade de gerir e administrar processos e pessoas, com observância dos níveis graduais de tomada de decisão, bem como capaz para atuar nos niveis de comportamento microorganizacional, mesoorganizacional e macroorganizacional.” (MEC, 2005).

Evidencia-se, assim, que a ocupação é envolta por questões de gênero, de cultura organizacional e de aspectos legais que implicam estudos em distintas áreas para o entendimento da natureza de seu conhecimento, o qual é fruto da interdisciplinaridade de teorias, contando com a Administração como sua ciência basilar.

\section{Conclusão}

A constituição da ciência secretarial impõe uma análise sob ângulos variados de objetos que possuem limites diferenciados de conhecimento. Valer-se de óticas isoladas, além de comprometer a dialética necessária para a compreensão da natureza dos próprios objetos enfocados, também pode fundar uma falsa cientificidade, com consequências danosas ao progresso dos estudos na área. A pretensão de elevar o Secretariado à categoria de uma ciência com características epistemológicas independentes das áreas de conhecimento nas quais ele se tem apoiado exime o estudioso de procurar compreender uma práxis feita de um arcabouço de conceitos que perpassa, necessariamente, pelos aspectos culturais e organizacionais conferidos à sua identidade histórica. Assim, o estudioso do secretariado encontra-se dentro de uma área de conhecimentos aplicados que se formou segundo indubitáveis relações culturais e de gênero, de forma que a leitura epistemológica é cerceada por influências múltiplas, que vão muito além do cenário fornecido por objetos de contorno isolado.

O secretário executivo atua em apoio aos líderes empresariais no que toca aos processos administrativos, função majoritariamente exercida por mulheres. Já no âmbito governamental, torna-se um cargo de apoio estratégico dentro dos setores encarregados de gerenciar a máquina pública. A complexidade dos conceitos com os quais a práxis do Secretariado está envolvida estende-se para muito além de teorias que podem ser simplificadas em uma única ciência. Disciplinas como Administração, Direito, Arquivística e Contabilidade fazem parte indissociável da síntese dos conhecimentos do Secretariado, gerando a interdisciplinaridade que o caracteriza como um campo das Ciências Sociais Aplicadas, em estreita relação com as Ciências Humanas. Porém, a dimensão epistemológica dessa mistura teórica não atinge a transdisciplinaridade, uma vez que, conforme aqui demonstrado, há a prevalência dos pressupostos da ciência da Administração, norteadora da práxis secretarial. 
Assim, embora se trate de uma ocupação milenar, o Secretariado não constitui uma ciência autônoma, fato que, em absoluto, desvaloriza os profissionais da área no terreno científico. Os fundamentos da atividade secretarial comprovam a utilização de diversas ciências interdisciplinares, sem as quais a ocupação seria seguramente prejudicada, tendo em vista que todas elas permitem o aperfeiçoamento contínuo tanto da práxis, quanto da compreensão epistemológica. Defender a valorização do Secretariado pelo simples estabelecimento do status de ciência particular é relegar questões realmente essenciais tanto do campo teórico, quanto da atuação profissional. 


\section{Referênclas}

ALLPORT, Gordon Willard. Personality: a psychological interpretation. New York: Henry Holt anda Company, $1945 \cdot 588$ p.

BACHELARD, Gaston. A formação do espírito científico. Rio de Janeiro: Contraponto, 2002. 316p.

BISCOLI, F. R. V.; LOTTE, R. I. Reflexões teóricas sobre a importância da comunicação em Secretariado Executivo. Expectativa, Toledo: Edunioeste, v. 5, n 5, p. 157-172, 2006.

BRASIL. Lei n. 7.377, de 30 de setembro de 1985. Dispõe sobre o exercício da profissão de secretário e dá outras providências. Diário Oficial da União, Brasilía, 1 out. 1985, Seção 1, p. 14314.

BRASIL. Lei n. 9.261, de 10 de janeiro de 1996. Altera a redação dos incisos I e Il do art. $2^{\circ}$, o caput do art. $3^{\circ}$, o inciso VI do art. $4^{\circ}$ e o parágrafo único do art. $6^{\circ}$ da Lei n 7.377, de 30 de setembro de 1985. Diário Oficial da União, Brasília, 11 jan. 1996, Seção 2, p. 393.

BRASIL, Lei n. 11.204, de 05 de dezembro de 2005. Altera a Lei $n^{0}$ 10.683, de 28 de maio de 2003, que dispõe sobre a organização da Presidência da República e dos Ministérios; autoriza a prorrogação de contratos temporários firmados com fundamento no art. 23 da Lei $n^{\circ}$ 10.667, de 14 de maio de 2003; altera o art. $4^{\circ}$ da Lei $n^{\circ}$ 8.745, de 9 de dezembro de 1993, e a Lei $n^{\circ}$ 11.182, de 27 de setembro de 2005; e dá outras providências. Diário Oficial da União, Brasília, 06 dez. 2005, Seção 1, p. 1

BUNGE, Mario. La investigación científica. Barcelona: Ariel, 1969.

Epistemologia: curso de atualização. Tradução de Cláudio Navarra. São Paulo: T. A. Queiroz, 1980. 246 p.

ESPANHA. Real Decreto $n^{\circ}$. 1.658, de 22 de julho de 1994. Establece el titulo de tecnico superior en secretariado y las correspondientes enseñanzas minimas. Item 2.1.1 Competencia general. Boletín Oficial del Estado. Madrid, 30 set. 1994, n. 234, p. 30320 .

GARCIA, Elisabeth Virag. Muito prazer, sou a secretária do senhor. São Caetano do Sul: s/e, 1999. 140 p.

GUIMARÃES, Marcio Eustáquio. O livro azul da secretária moderna. 19. ed. São Paulo: Érica, 2001. 276 p.

GUIMARÃES, Nadya Araujo. Gênero e Trabalho. Revista Estudos Feministas. Florianópolis: UFSC, maio-agosto, v. 12, n. 2, 2004.

HOELLER, Patrícia A. Freitas. A natureza do conhecimento em Secretariado Executivo. Expectativa. Toledo: Edunioeste, v. 5, nº 5, p. $139-145,2006$.

MACDONALD, Eleanor. The developing role of the secretary. Journal Education + Training. Bingley (UK): MCB UP Ltd, nov-dez, p. $15-17,1988$.

MAQUIAVEL, Nicolau. O Príncipe. 18. ed. Rio de Janeiro: Paz e Terra, 1996. 136p.

MARCHELLI, Paulo Sérgio. Pluralismo e reducionismo do método científico: a visão interdisciplinar em Piaget e Popper. Revista Tempo e Memória. São Paulo, n. 2, p. 121-132, jan-jul, 2004.

MARSHALL, Alfred. Princípios de economia: tratado introdutório. v. 1. Tradução de Rômulo Almeida e Ottolmy Strauch. São Paulo: Abril Cultural, 1982. $272 \mathrm{p}$.

MARROU, Henri-Irenee. História da educação na antigüidade. 5. ed. Tradução de Mário Leonidas Casanova. São Paulo: Editora Pedagógica e Universitária Ltda., 1990. 639 p. Título original: Histoire de l'éducation dans l'Antiquité.

MINISTÉRIO DA EDUCAÇÃO E CULTURA. Diplomas de graduação. Disponível em: http://portal.mec.gov.br/sesu/index.php?option=content\&task=view\&id=497\&ltemid=420. Acesso em 01.06.2008.

MORETTO, Amilton; JESUS, Cláudio Roberto de. Perfil e tendências da profissional secretária(o) no Brasil. Campinas: Centro de Estudos Sindicais e de Economia do Trabalho - CESIT/Universidade Estadual de Campinas-UNICAMP, 1999.

NONATO JUNIOR, Raimundo. Epistemologia do Secretariado Executivo: por uma teoria do conhecimento em Secretariado. In: XVI Congresso Nacional de Secretariado. Anais (Resumos). Brasília: Federação Nacional de Secretariado, 2008. p. 7-8.

POPPER, Karl. A lógica da pesquisa científica. São Paulo: Cultrix / Edusp, 1975. 567p. 
PROGRAM FOR THE SUPPORT OF WOMEN'S LEADERSHIP AND REPRESENTATION - PROLEAD. Moving into Power: Changing the Rules of the Game. Disponivel em

http://www.iadb.org/sds/prolead/publication/publication _ 7 1785 e.htm. Acesso em og de jun. 2008.

REICH, Robert B. O trabalho das nações: preparando-nos para o capitalismo do Século 21. 2. ed. Sao Paulo: Educator, 1994.

RIDGEWAY, Christopher. The role of the secretary in personnel management. Leadership e Organization Development Journal, Bingley (UK): MCB UP Ltd, vol. 3, p. 17-20, 1982.

SANTOMÉ, Jurjo Torres. Globalização e Interdisciplinaridade: O currículo integrado. Tradução de Cláudia Schilling. Porto Alegre: Artes Médias, 1998. 275 p. Texto Original: Globalización e interdisciplinariedad: el curriculum integrado.

SCHVINGER, Amaryllis, PRADO, Danda, CASTRO, Jacqueline. Secretária: uma ambigüidade em feitio de profissão. Caderno de Pesquisa da Fundação. São Paulo: Carlos Chagas, n.54, p. 85-97, ago. 1985.

SOUINELO, Ana Paulo, BERTOLDO, Sandra Regina F. (Org.) A profissão de secretário executivo: trajetória e perspectivas. Rondonóplis: AP Editores, 2002. $113 \mathrm{p}$.

TAYLOR, Frederick W. Princípios de administração científica. 7 ed. São Paulo: Atlas, 1979. 134 p.

TRUSS, Catherine J. G. The secretarial ghetto: myth or reality? Work, Employment \& Society. Durham (UK): BSA Publications Ltd, v. 7, n. 4, p. 561-584, 1993. 